\title{
One-year evaluation of the treatment of hydrocephalus associated with Galen's vein aneurysm: about 3 cases in a country with limited health resources
}

\author{
Louncény Fatoumata Barry ${ }^{*}$ Y Yakhya Cisse, Mohameth Faye, Mouhamadou Moustapha Ndongo, Mhaks Malangu, \\ Amidou Adjamou, Momar Codé Ba and Seydou Boubakar Badiane
}

\begin{abstract}
Background: Aneurysm of vein of Galen is a rare congenital arteriovenous malformation. Clinical manifestations depend on the age of discovery. Endovascular embolization is currently the treatment of choice. This technique is not always available in developing countries. We report 3 cases treated symptomatically by endoscopic third ventriculostomy and ventriculoperitoneal shunt.

Cases presentation: Three patients, 7 months, 15 years, and 26 years old, received in a table of acute intracranial hypertension, associated for the first one with convulsions and for the second one with moderate heart failure. Bain CT scan revealed triventricular hydrocephalus secondary to sacciform dilatation of the Galen's vein in all three patients, requiring symptomatic treatment by endoscopic third ventriculostomy for the first patient and ventriculoperitoneal shunt for the other two in the absence of an adequate clinical platform for endovascular embolization. The evolution was favorable at 1 year's follow-up.

Conclusion: Galen's vein aneurysm is a rare vascular malformation. It mainly affects newborns and small children but can be discovered in adulthood. Endovascular embolization is its treatment of choice. This technique is not always available in some countries, which makes it necessary to resort to symptomatic treatment by ventricular shunt.
\end{abstract}

Keywords: Aneurysm, Galen, Hydrocephalus, Embolization, Shunt

\section{Background}

Galen's vein aneurysm is a rare, complex, congenital intracranial arteriovenous malformation (AVM), associating a pseudo aneurysmal dilatation of Galen's vein with one or more arteriovenous fistulas [1]. It accounts for less than $1 \%$ of all intracranial AVMs [2]. Clinical manifestations depend on the age of discovery and the diagnosis is usually made antenatally on obstetric ultrasound, or in the neonatal period in a congestive heart failure picture, or postnatally. The clinical presentation

\footnotetext{
* Correspondence: lousbarryzion29@gmail.com

Neurosurgery Clinic, Fann University Hospital, P.O. Box 5035, Dakar, Senegal
}

in adults is exceptional [3]. The prognosis is often poor, with $50 \%$ post-natal mortality and a high risk of neurological sequelae $[4,5]$. Several treatments have been proposed successively, curative surgery with its difficulties at first and more recent embolization [6, 7]. These treatments are not always available in underdeveloped countries, particularly in the southern countries.

We report 3 cases treated in the context of a country with limited health resources by endoscopic third ventriculostomy (ETV) and ventriculoperitoneal shunt (VPS), in order to demonstrate the effectiveness of cerebrospinal fluid shunt in the treatment of hydrocephalus associated with Galen's vein aneurysm.

\section{Springer Open}

(๑) The Author(s). 2021 Open Access This article is licensed under a Creative Commons Attribution 4.0 International License, which permits use, sharing, adaptation, distribution and reproduction in any medium or format, as long as you give appropriate credit to the original author(s) and the source, provide a link to the Creative Commons licence, and indicate if changes were made. The images or other third party material in this article are included in the article's Creative Commons licence, unless indicated otherwise in a credit line to the material. If material is not included in the article's Creative Commons licence and your intended use is not permitted by statutory regulation or exceeds the permitted use, you will need to obtain permission directly from the copyright holder. To view a copy of this licence, visit http://creativecommons.org/licenses/by/4.0/. 


\section{Cases presentation}

\section{Case no. 1}

Case no. 1 is a 7-month-old infant from full-term pregnancy and delivered vaginally with no notable features at birth (APGAR, 10/10), received in consultation for progressive macrocrania and generalized tonic-clonic convulsive seizures evolving from 1 month on reception, associated with crying and vomiting. The examination found an infant in a good staturo-ponderal state and good psychomotor development. The neurological examination was without notable particularities. At the cephalic extremity, a macrocrania (cranial perimeter $50.5 \mathrm{~cm}$ ), a tense anterior fontanel, and collateral venous scalp circulations were noted. He showed no signs of cardiac insufficiency.

Brain computed tomography (CT) revealed triventricular hydrocephalus secondary to a large Galen's vein aneurysm (Fig. 1). The indication for an ETV was placed and carried out as an emergency; the evolution was marked by the regression of the signs of intracranial hypertension $(\mathrm{ICH})$ in the immediate postoperative aftermath and the frequency of seizures and at 1 year's follow-up by the stabilization of the cranial perimeter and the complete cessation of seizures.

\section{Case no. 2}

Case no. 2 is a 15 -year-old adolescent, chronic cephalalgic with notions of palpitation episodes evolving over the years, received in an acute $\mathrm{ICH}$ table with intense headache and vomiting. The examination finds a patient in good general condition without neurological particularities. The cardiac examination finds a carotid dance with signs of Musset and a systolic murmur in the mitral focus. The brain CT scan revealed triventricular hydrocephalus secondary to a Galen's vein aneurysm (Fig. 2). Cardiac Doppler ultrasound showed dilatation of the right heart chambers with functional valvular insufficiency without alteration of systolic function. The indication for VPS was placed and performed as an emergency procedure, and the evolution was marked by the regression of the signs of $\mathrm{ICH}$ in the immediate postoperative period. The patient was subsequently referred to cardiology for the management of his heart disease. At 1 year's follow-up, the signs of ICH completely disappeared without complications related to VPS.

\section{Case no. 3}

Case no. 3 is a 26-year-old chronic cephalalgic patient, received in consultation in an acute $\mathrm{ICH}$ table with diffuse and intense headache, vomiting evolving for 48 hours at reception. The examination found a patient in good general condition and without particularities on neurological examination. The brain CT scan had revealed triventricular hydrocephalus secondary to a Galen's vein aneurysm (Fig. 3).

The VPS indication was placed and performed as an emergency procedure. The evolution was marked by the regression of the signs of $\mathrm{ICH}$ in the immediate postoperative period and at 1 year of follow-up by the complete disappearance of the signs of $\mathrm{ICH}$ and without complications related to VPS.

\section{Discussion}

First described by Jaeger, Forees, and Dandy in 1937 [4, 8], Galen's vein aneurysm is an embryonic malformation occurring between the 6th and 11th week of pregnancy, consisting of a set of fistulas leading to an abnormally persistent and dilated Markowski's porencephalic median vein which is the embryological precursor of Galen's vein (described by Pergame Galien in the second century $\mathrm{AD}$ in animals as a deep venous structure behind the third ventricle which bears his name) [9].

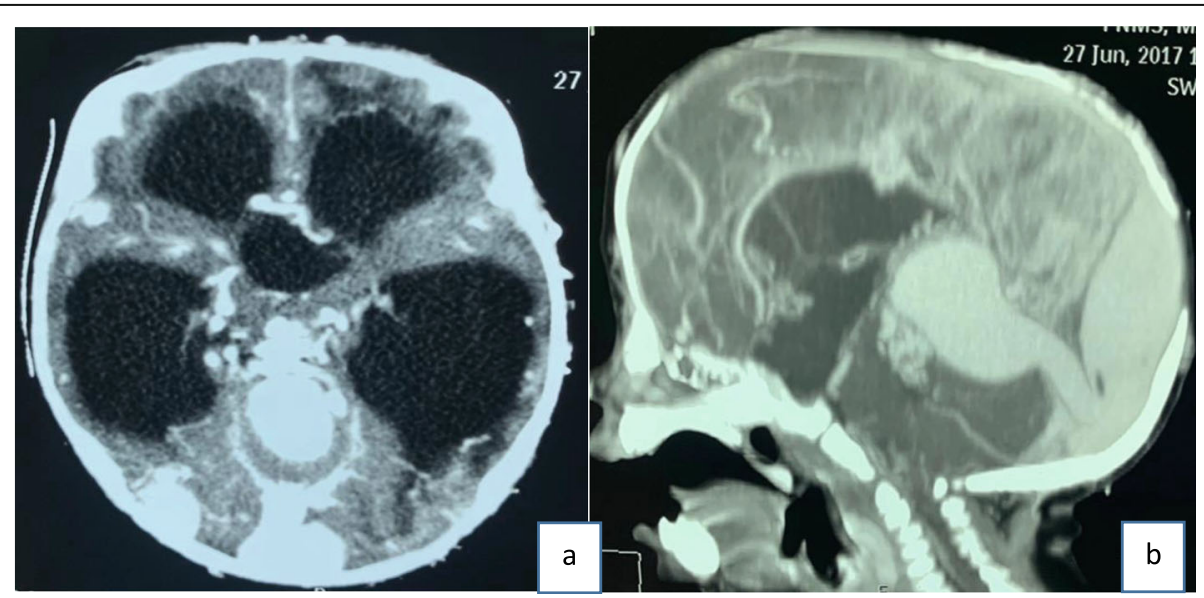

Fig. 1 a Brain CT scan with contrast agent injection, axial section, and $\mathbf{b}$ brain angio CT scan, sagittal section: triventricular dilatation secondary to saccular dilatation of the Galician vein 


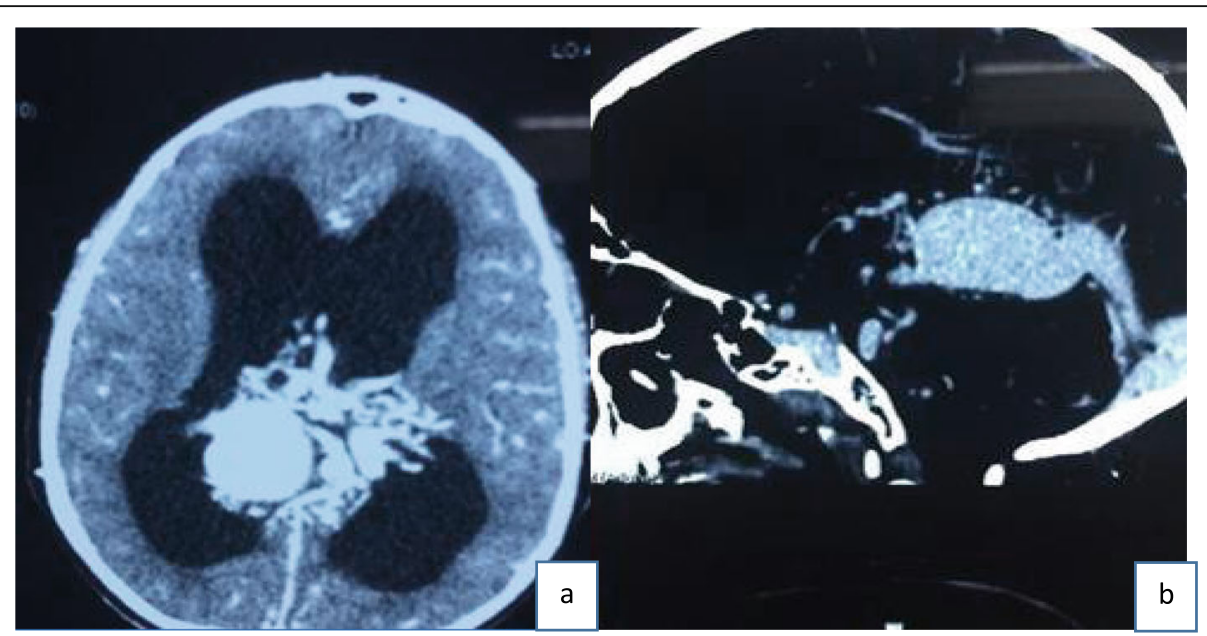

Fig. 2 a Brain CT scan with injection of contrast agent, axial section, and $\mathbf{b}$ brain angio CT scan, sagittal section: triventricular dilatation secondary to saccular dilatation of the Galician vein

It is a rare congenital condition that accounts for less than $1 \%$ of intracranial AVMs $[2,9]$. Although rare, it is one of the most frequently diagnosed AVMs in children before and after birth. It mainly affects newborns and infants: two thirds of cases are diagnosed before the age of 28 months $[1,10]$. This is the case of our first observation, which was diagnosed at 7 months of age. Although congenital in origin, the clinical manifestations of Galen's vein aneurysm can appear at different ages. Three clinical groups have been established [11]:

Group 1. Aneurysms occurring at or soon after birth due to heart failure and head murmur. Heart failure may be associated with cyanosis.

Group 2. Symptoms appear between 1 and 6 months after birth and are characterized by hydrocephalus and milder heart failure. A cranial murmur may be heard.
Group 3. Cases in which neonatal problems are absent, and the diagnosis is made at a later age with the appearance of subarachnoid hemorrhage, convulsions, hydrocephalus, symptoms of the "flying phenomenon" or limitation of upward gaze (Parinaud's syndrome).

Our 3 observations were revealed by a table of acute $\mathrm{ICH}$ associating for the first observation generalized seizures and for the 2nd observation a moderate heart failure. This ICH was related to triventricular hydrocephalus diagnosed in our study by brain CT scan. This hydrocephalus is thought to be related to cerebral venous hypertension, caused by the fistula and responsible for a decrease in cerebrospinal fluid resorption or by obstruction of the Sylvius aqueduct $[1,5]$. As for the age of revelation, it was longer for our 2nd and 3rd observations, 15 and 26 years, respectively. This variability

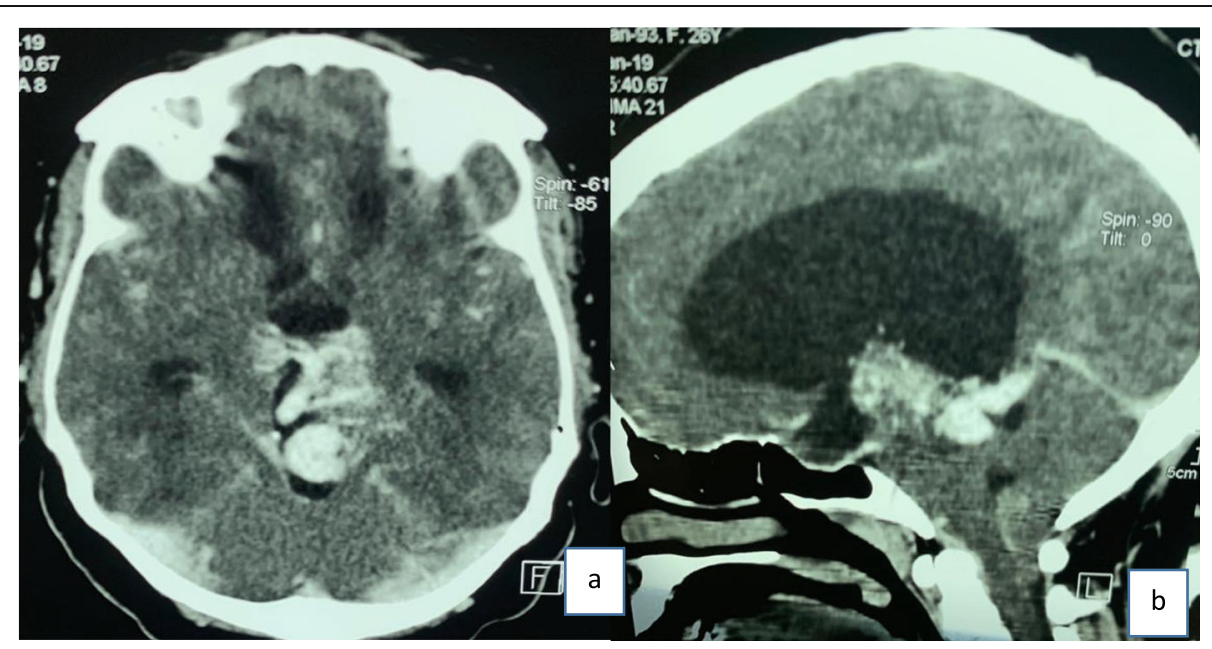

Fig. 3 Brain CT scan with injection of contrast agent, a axial section and $\mathbf{b}$ sagittal section: triventricular dilatation secondary to sacciform dilatation of the Galien vein 
in clinical expression over time could be explained by the angioarchitectural varieties of vascular origin that evolve over time. Two angioarchitectural varieties exist: the choroidal variety with contribution from all choroidal arteries, which is expressed in the neonatal period, and the mural variety with presence of arteriovenous fistulas with the porencephalic median vein, which is expressed in the neonatal period moderately or later in childhood or adulthood [12].

The diagnosis is most often made during routine antenatal ultrasound examinations. In the neonatal period, transfontanel ultrasound is currently a routine examination performed during the first year of life. Coupled with Doppler, ultrasonography makes it possible to study the deep cerebral vessels and finds the same semiological elements as in the antenatal period [13]. In computed tomography, arteriovenous malformations are spontaneously discreetly hyperdense and sometimes present calcifications within them. After injection, a very intense vascular type of contrast is observed. The malformities vessels appear as tubular and curvilinear opacities. The deep venous drainage of the malformation is often clearly identifiable in the form of a tubular opacity draining into a dilated Galen vein [14]. Magnetic resonance imaging (MRI) is the most sensitive examination for the search for parenchymal lesions and must be systematically performed. MRI makes it possible to better specify the anatomical relationships of the malformation, particularly with deep brain structures. In aneurysmal dilatation, arteries and veins are empty of signal on T1 and $\mathrm{T} 2$ sequences $[3,15]$. For our 3 observations, the diagnosis was made by brain CT scan. MRI was not performed in any of our patients due to the high cost and relative availability of the test.

Differential diagnoses of Galen's great vein aneurysm are essentially made with fluid lesions of the midline, including pineal gland cyst, colloid cyst, arachnoid cyst, and subependymal pseudocysts [16].

Once surgical with a disappointing result, endovascular embolization methods are currently the treatment of choice with a satisfactory success rate but require a team of experienced neuroradiologists. The goal of the treatment is the occlusion of the shunts of the malformation. Its effectiveness depends largely on the size of the malformations and the complications developed [9]. This technique has not been performed in our patients due to the lack of an adequate technical platform. Therefore, we considered that cerebrospinal fluid derivation by ETV performed in one patient (observation 1) or VPS performed in 2 patients (observations 2 and 3) would seem to relieve our patients. However, the literature mentions that VPS could be one of the factors that increase bleeding and exacerbate the symptoms of Galen's vein aneurysm [17]. Some authors [18, 19] advocate
ETV as a relatively recent alternative to bypass valve implantation, mainly used in obstructive hydrocephalus with an overall success rate of about $75 \%$ and a low complication rate of less than $5 \%$.

Over drainage is another disadvantage of VPS which can cause symptoms later on, such as subdural hematoma, hygroma, and slit ventricles. Such complications can be avoided with ETV, as this would not change the balance between supra- and infra-tentorial pressures [18]. Without ignoring the fact that even in environments with an adapted technical platform, embolization is a major treatment and has a success rate of about $60 \%$ according to some studies $[20,21]$. Despite the risks of complications related to VPS, no cases of complications were noted in our study at one year of follow-up.

\section{Conclusion}

Galen's vein aneurysm is a rare congenital vascular malformation. This condition mainly affects newborns and small children but can be discovered in adulthood as our observations illustrate. Endovascular embolization is currently the treatment of choice for this pathology with a survival rate that is constantly evolving according to the teams. This technique is not always available in developing countries such as ours, forcing some practitioners to resort to symptomatic treatments such as in our case ETV or VPS.

\section{Abbreviations}

AVM: Arteriovenous malformation; ETV: Endoscopic third ventriculostomy; VPS: Ventriculoperitoneal shunt; CT: Computed tomography; ICH: Intracranial hypertension; MRI: Magnetic resonance imaging

\section{Acknowledgements}

Not applicable

\section{Authors' contributions}

All the authors (LFB, YC, MF, MMN, MM, AA, MCB, SBB) meet the 4 criteria of the International Committee of Medical Journal Editors (ICMJE): (1) substantial contributions to research design or methods or to acquisition, analysis, or interpretation of data; (2) preliminary writing of the article or its critical review involving significant contribution to the intellectual content; (3) final approval of the version to be published; and (4) commitment to assume accountability for all aspects of the research by ensuring that the issues related to the accuracy or integrity of any part of the work is examined in a manner that appropriate and resolute. The authors have read and approved the final manuscript.

\section{Funding}

Not applicable

Availability of data and materials Not applicable

\section{Declarations}

Ethics approval and consent to participate

Our study was exempted from the obligation to obtain ethical approval by the ethical and moral committee of "Fann University hospital" (www.chnufann.com; telephone 00221338691818).

Consent to participate of these case reports was obtained for the first two observations by the parents and by the patient herself for the third observation. 


\section{Consent for publication}

Consent for publication of these case reports and accompanying images was obtained for the first two observations by the parents and by the patient herself for the third observation.

\section{Competing interests}

The authors declare that they have no competing interests.

Received: 13 November 2020 Accepted: 24 May 2021

Published online: 20 September 2021

\section{References}

1. Beucher G, Fossey C, Belloy F, Richter B, Herlicoviez M, Dreyfus M. Diagnostic anténatal et prise en charge d'un anévrysme de la veine de Galien. Revue de la littérature illustrée par une observation personnelle. J Gynecol Obstet Biol Reprod. 2005;34(6):613-9. https://doi.org/10.1016/S03 68-2315(05) $82889-3$

2. Maheut J, Santini JJ, Billard C. Symptomatologie clinique de l'anévrysme de l'ampoule de Galien. Résultats d'une enquête nationale. Neurochirurgie. 1987:33(4):285-90

3. Abdoulaziz S, Kouda F, Tahirou S, Haloua M, Badreeddine A, Lamrani YA, et al. Présentation IRM d'une malformation anévrismale de la veine de Galien révélée par un état de crise épileptique : à propos d'une observation. Pan Afr Med J. 2020;3:2-7.

4. Lasjaunias P, Hui F, Zerah M, Garcia-Monaco R, Malherbe V, Rodesch G, et al. Cerebral arteriovenous malformations in children. Management of 179 consecutive cases and review of the literature. Childs Nerv Syst. 1995;11(2): 66-79. https://doi.org/10.1007/BF00303807.

5. Jones BV, Ball WS, Tomsick TA, Millard J, Crone KR. Vein of Galen aneurysmal malformation: diagnosis and treatment of 13 children with extended clinical follow-up. Am J Neuroradiol. 2002;23(10):1717-24.

6. Amacher $A$, Shillito $J \mathrm{~L}$. The syndromes and surgical treatement of aneurysms of the great vein of Galen. J Neurosurg. 1973:39:89-98

7. Merland JJ, Laurent A, Reizine D. Malformation artério-veineuse de la région de l'ampoule de Galien. Aspects anatomiques, cliniques et évolution du traitement endo-vasculaire (1979-1986). A propos de 10 cas. Neurochirurgie. 1987:33(4):349-52.

8. Mayberg MR, Zimmermanzimmer Man C. Vein of Galenaneurysm associated with durai AVM and straight sinus thrombosis J. Neursurg. 1988;68(2):28891. https://doi.org/10.3171/jns.1988.68.2.0288.

9. Menovsky T. Van Overbeeke Jj. Cerebral arteriovenous malformations in childhood: state of the art with special reference to treatment. Eur J Pediatr. 1997;156(10):741-6. https://doi.org/10.1007/s004310050703.

10. Frawley GP, Dargaville PA, Mitchell PJ, Tress BM, Loughnan P. Clinical course and medical management of neonates with severe cardiac failure related to vein of Galen malformation. Arch Dis Child Fetal Neonatal Ed. 2002 Sep; 87(2):F144-9. https://doi.org/10.1136/fn.87.2.F144.

11. Al-Watban J, Banna M. Infantile cardiomegaly as a complication of vascular malformations of the brain: report of two cases. Ann Saudi Med. 1988;8(5): 373-6. https://doi.org/10.5144/0256-4947.1988.373.

12. Lasjaunias P, Garcia-Monaco R, Rodesch G, ter Brugge K, Zerah M, Tardieu $M$, et al. Vein of Galen malformation. Endovascular managment of 43 cases. Childs Nerv Syst. 1991;7(7):360-7. https://doi.org/10.1007/BF00304199.

13. Vintzileos AM, Eisenfeld LI, Campbell WA, Herson VC, DiLeo PE, Chameides L. Prenatal ultrasonic diagnosis of arteriovenous malformation of the vein of Galen. Am J Perinatol. 1986;3(03):209-11. https://doi.org/10.1055/s-2007999869.

14. Borthne A, Carteret M, Baraton J, Courtel J, Brunelle F. Vein of Galen vascular malformations in infants: clinical, radiological and therapeutic aspect. Eur Radiol. 1997;7(8):1252-8.

15. Messori A, Polonara G, Salvolini U. Prenatal diagnosis of a vein of Galen aneurysmal malformation with fetal MR imaging study. Am J Neuroradiol. 2003;24(9):1923-5.

16. Pilu G, Falco P, Perolo A. Differential diagnosis and outcome of fetal intracranial hyoechoic lesions: report of 21 cases. Ultrasound Obstet Gynecol. 1997 Apr;9(4):229-36. https://doi.org/10.1046/j.1469-0705.1997.0904 0229.x.

17. Abdoulaye D, Mohameth F, El Hassimi CM, Mbaye T, Code BM, Boubakar BS, Late discovery of a vein of galen aneurysmal malformation complicated with hydrocephalus: a case report. Open J Modern Neurosurg. 2020;2(10): 254-9.
18. Champeaux C, Botella C, Lefevre C, Devaux B. Obstructive hydrocephalus caused by an unruptured arteriovenous malformation successfully treated by endoscopic third ventriculostomy after shunt dysfunction. Turk Neurosurg. 2018;28(3):500-4. https://doi.org/10.5137/1019-5149.JTN.19435-1 6.2

19. Mohameth F, Mbaye T, Malangu M, Mualaba C, Bouih M, Barry LF, et al. Galen vein aneurysm: problem of management in an under-equipped neurosurgical environment about a case and review of the literature. J Med Medl Res. 2020;32(13):83-7.

20. Birgitta $R$, Olof $R$, Jan $G$, Petru $L$, et al. Endovascular treatment of vein of Galen aneurysmal malformation using rapid ventricular pacing: a case report. Interv Neuroradiol. 2017;23(1):97-101.

21. Alejandro B, Michelle S, Walter M, Melia D, Saadi G. Vein of Galen aneurysmal malformation: advances in management and endovascular treatment. Neurosurgery. 2019;84(2):469-78.

\section{Publisher's Note}

Springer Nature remains neutral with regard to jurisdictional claims in published maps and institutional affiliations.

\section{Submit your manuscript to a SpringerOpen ${ }^{\circ}$ journal and benefit from:}

- Convenient online submission

- Rigorous peer review

- Open access: articles freely available online

- High visibility within the field

- Retaining the copyright to your article

Submit your next manuscript at $\boldsymbol{\nabla}$ springeropen.com 